\title{
Studi Pemodelan Respon Polarisasi Terinduksi dalam Kawasan Waktu (TDIP) terhadap Kandungan Mineral Logam, Sebuah Hasil Awal
}

\author{
Yatini ${ }^{1}$, Djoko Santoso ${ }^{2}$, Agus Laesanpura ${ }^{2}$, Budi Sulistijo ${ }^{3}$ \\ ${ }^{1}$ Prodi Geofisika, FTM, UPN "Veteran" Yogyakarta \\ ${ }^{2}$ Departemen Geofisika, FTTM, Institut Teknologi Bandung \\ ${ }^{3}$ Departemen Pertambangan, FTTM, Institut Teknologi Bandung \\ E-mail: jeng_tin2004@yahoo.com
}

Received 01-07-2014, Revised 01-08-2014, Accepted 05-09-2014, Published 31-10-2014

\begin{abstract}
Modelling studies of Time Domain Induced Polarization (TDIP) performed to obtain the relationship between parameters responses to metallic mineral content. This study includes mathematical, forward, physical and inversion modelling. Mathematical modelling is done by solving the Laplace equation to obtain the IP responses. Forward modelling is done by developing a numerical workflow to generate theoretical curves. Physical modelling obtained the data from various parameters of target measurement. TDIP responses that compared with the theoretical curves are the results of mathematical modelling. The best response of IP can be obtained by inversion modelling. TDIP responses measurement by varying target's metallic mineral content is done for understanding the relationship between them. The amplitude of IP responses in forward modelling is determined by target's radius and depth ratio, and ratio of background resistivity and target's resistivity. The higher target's radius and depth ratio, the higher the amplitude. There is a good correlation between TDIP responses to the presence of the target and the possibility of metallic mineral content in target.
\end{abstract}

Keywords : mathematical modelling, forward modelling, physical modelling and inversion modeling

\section{ABSTRAK}

Studi pemodelan Time Domain Induced Polarization (TDIP) dilakukan untuk memperoleh hubungan parameter respon TDIP terhadap kandungan mineral logam. Studi ini meliputi pemodelan matematika, pemodelan kedepan, pemodelan fisis dan pemodelan inversi. Pemodelan matematika pada prinsipnya adalah menyelesaikan persamaan Laplace untuk memperoleh respon IP teoritis. Pemodelan kedepan dilakukan dengan membangun alur numerik untuk menghasilkan kurva-kurva teoritis. Respon TDIP berbagai parameter target pengukuran diperoleh dari pemodelan fisis. Data ukur respon TDIP ini yang akan dibandingkan dengan kurva-kurva teoritis hasil pemodelan matematik. Dengan cara inversi, maka akan diperoleh respon IP yang paling baik. Pengukuran respon TDIP pada variasi kadar mineral logam dalam target dilakukan untuk mengetahui hubungan antara keduanya. Amplitudo respon IP pemodelan kedepan ditentukan oleh rasio jari-jari dan kedalaman target dan rasio resistivitas medium latar dan target. Semakin besar rasio jari-jari dan kedalaman target, maka amplitudo semakin besar. Terdapat korelasi yang baik, antara respon TDIP terhadap keberadaan target dan kemungkinan kandungan besi dalam target.

Kata kunci : pemodelan matematik, pemodelan kedepan, pemodelan fisis, inversi 


\section{PENDAHULUAN}

Metode Induced Polarization (IP) adalah bagian dari metoda Geofisik yang memanfaatkan sifat polarisasi karena adanya arus listrik yang dilewatkan dalam medium. Metode ini muncul karena keterbatasan metode Geolistrik. Salah satu teknik pengukuran metode ini adalah dalam kawasan waktu, oleh karena itu disebut Time Domain Induced Polarization (TDIP). Metode IP banyak digunakan untuk eksplorasi base metal. Salah satu parameter terukur yaitu chargeabilitas, dapat dipakai untuk membedakan sifat polarisabel bawah permukaan. Chargeabilitas yang tinggi merupakan indikasi adanya mineral logam. Mineral logam inilah yang merupakan target dari eksplorasi menggunakan metoda IP.

Terjadinya polarisasi terinduksi disebabkan karena kombinasi beberapa proses kimia fisika yang terjadi karena aliran arus listrik pada medium. Secara garis besar ada dua mekanisme yang dikenal yaitu adanya gerakan ion-ion dalam fluida yang melewati struktur batuan (polarisasi membran), dan perbedaan konduktifitas ionik dan elektronik karena adanya mineral logam (polarisasi elektroda). Polarisasi membran biasa terjadi pada batuan yang tidak mengandung mineral logam. Polarisasi elektroda terjadi karena terdapatnya kontak antara mineral konduktip dari batuan dan larutan dalam pori-pori batuan. Polarisasi membran dipengaruhi porositas, kandungan lempung dan peranan fluida sebagai pengalir arus. Secara umum polarisasi elektroda jauh lebih besar dari pada efek IP normal, tergantung dari keberadaan mineral logam dalam batuan ${ }^{[1]}$. Hal ini berarti peranan fluida dan mineral logam adalah dua hal yang sangat dominan sebagai penyebab efek polarisasi terinduksi. Apabila pada medium polarisasi elektroda lebih mendominasi, maka kandungan mineral logam dan elektrolit dalam medium tersebut menjadi faktor utama terhadap respon IP yang terukur dipermukaan.

Hubungan antara kandungan mineral logam dalam medium bawah permukaan dan respon polarisasi terinduksi yang terukur belum diketahui dengan pasti. Secara umum respon IP dipengaruhi oleh kondisi (sifat fisis) medium. Chargeabilitas semakin besar jika kandungan sulfida semakin tinggi dan akan mengecil jika ukuran butir semakin besar, sedangkan nilai resistivitasnya tidak turun terus menerus terhadap kenaikan kandungan sulfida $^{[2]}$. Adanya mineral lempung (clay) dalam batuan sangat mempengaruhi respon IP. Adanya mineral lempung yang berinteraksi dengan air tanah dapat menimbulkan efek polarisasi terinduksi dan memperkecil resistivitasnya ${ }^{[3]}$. Chargeabilitas juga berbanding lurus dengan volume pori pada tanah yang mengandung mineral besi $0,25 \%$ sampai $1,63 \%^{[4]}$. Hubungan antara besarnya respon IP terhadap luasan pori pada campuran pasir dan besi linier, tetapi tidak linier terhadap kandungan logam ${ }^{[5]}$. Chargeabilitas semakin besar jika kandungan sulfida semakin besar. Ukuran butir semakin besar, chargeabilitas semakin kecil untuk kandungan sulfida logam $6,3 \%{ }^{[6]}$.

Ukuran butir, porositas, kandungan mineral lempung, komposisi elektrolit dan kandungan mineral logam akan mempengaruhi respon IP. Dengan mengontrol ukuran butir, porositas, kandungan mineral lempung dan mengetahui jenis elektrolit, maka respon IP didominasi oleh kandungan mineral logam. Respon IP akan berubah jika kandungan mineral logam berbeda. Hubungan keduanya diharapkan diperoleh, dengan jalan membuat variasi kadar mineral logam dan mengukur respon IP.

Studi pemodelan dalam penelitian ini, dilakukan sebagai upaya untuk memperoleh hubungan kandungan mineral terhadap respon TDIP yang terukur dipermukaan. Pemodelan mencakup pemodelan matematik dan pembuatan model fisis skala 
laboratorium. Pemodelan matematika dimaksudkan untuk memperoleh respon TDIP secara teoritis, dengan cara mengambil model-model ideal dengan variasi parameter dan menghitung responnya (forward modelling). Mencari respon TDIP pada dasarnya adalah menyelesaikan persamaan Laplace, dengan sarat batas sesuai dengan model yang ditinjau. Hubungan antar parameter respon TDIP dipakai definisi Siegel dan Wait. Pemodelan ini akan menghasilkan respon TDIP teoritis, berupa kurva-kurva dengan berbagai variasi hubungan parameter.

Pembuatan model fisis dimaksudkan memperoleh hasil ukur parameter respon TDIP untuk kondisi bawah permukaan yang diketahui dengan pasti. Pada awalnya dilakukan pembuatan model fisis bawah permukaan yang mencontoh model geologi ideal dan mengukur respon TDIP nya. Dengan cara mengubah parameter fisis dan membuat variasi kadar mineral logam target pada model fisis dan mengukur respon TDIP nya, akan dihasilkan berbagai variasi parameter dengan berbagai variasi kandungan mineral logam. Selain itu juga dilakukan untuk model fisis dengan target benda ideal yang berbeda. Hubungan kuantitatip antara respon TDIP dan kandungan mineral logam diperoleh dengan jalan analisa pencocokan kurva-kurva respon TDIP hasil pemodelan matematik dan fisis.

\section{METODE}

Penelitian ini dimaksudkan untuk memperoleh respon IP untuk model matematik benda ideal (bola pejal dibawah permukaan). Menghasilkan proses pengukuran pada pemodelan fisis dan membuat analisis sifat fisis target pengukuran serta mengkaji hasil pemodelan matematik dan fisis.

Hubungan kandungan mineral logam dan parameter polarisasi terinduksi dalam domain waktu diperoleh dengan melakukan beberapa tahapan penelitian.

\section{Pemodelan matematis dan pemodelan kedepan.}

Model matematik yang di buat adalah model geometri ideal, yaitu model bola pejal dibawah permukaan. Pemodelan matematis dilakukan untuk menghitung respon IP secara teoritis. Untuk menghitung respon IP dipermukaan, maka persamaan Laplace harus diselesaikan dengan kondisi batas tertentu. Pemodelan matematik akan menghasilkan persamaan matematika respon TDIP yaitu resistivitas dan chargeabilitas terhadap fungsi parameter bawah permukaan. Variasi parameter bawah permukaan terhadap respon TDIP diperoleh dengan pemodelan kedepan.

\section{Pemodelan Fisis.}

Pembuatan model fisis dalam penelitian ini adalah salah satu langkah untuk memperoleh hubungan antara kandungan mineral logam dengan parameter respon TDIP. Selain itu juga akan diperoleh pengaruh teknik pengukuran terhadap parameter tersebut.

Pengaruh kandungan logam terhadap respon TDIP dicari dalam penelitian dengan pembuatan model fisis. Model fisis menggunakan box kaca (Gambar 1.) berukuran (200 $\mathrm{cm} \times 100 \mathrm{~cm}$ x $70 \mathrm{~cm}$ ). Respon TDIP diukur dipermukaan. Medium latar (host medium) digunakan air tanah yang mendekati sifat medium homogen isotrop ${ }^{[7]}$. Target digunakan bola pejal dengan diameter $10 \mathrm{~cm}$ dari bahan campuran pasir, besi dan semen dengan perbandingan tertentu ${ }^{[8],[9]}$. Kadar besi bervariasi dari $0 \%$ sampai $80 \%$. 

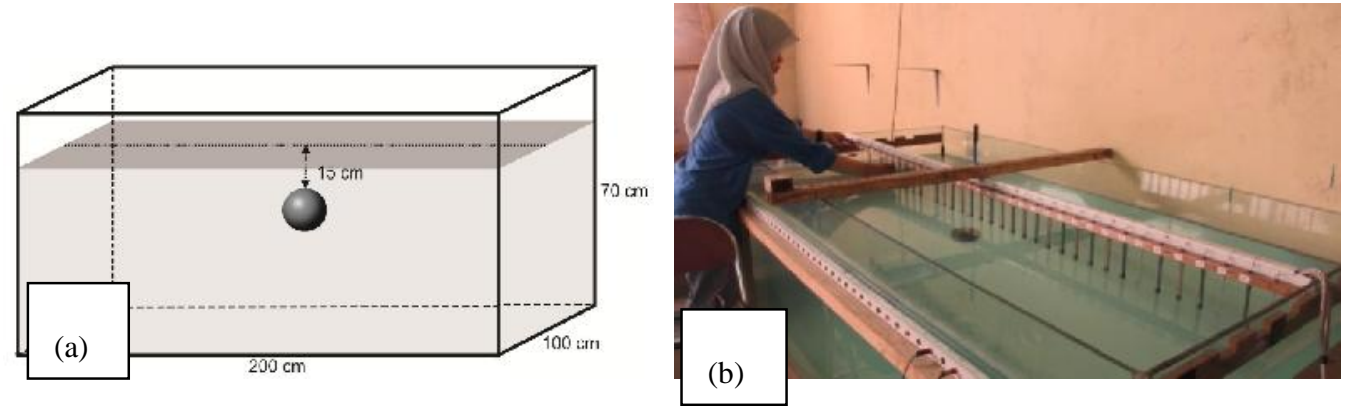

Gambar 1. (color online) (a). Sket box kaca pada pemodelan fisis TDIP dengan medium latar (host) air tanah dan target bola pejal berbagai kedalaman. (b). Pengukuran respon TDIP dipermukaan.

3. Pengukuran dan pengolahan hasil ukur.

Peralatan IP-Meter Syscal dipergunakan untuk mengukur respon TDIP pada model fisis. IP-Meter memiliki arus output max $1200 \mathrm{~mA}$, power max 100W dan siklus arus 0,5; 1 dan 2 detik. Porospot dan stainlessteel dipakai sebagai elektroda potensial dan arus, karena porospot sangat baik untuk elektroda potensial pada pemodelan fisis ${ }^{[10]}$. Pengukuran respon TDIP dipermukaan model fisis menggunakan konfigurasi Wenner dan Dipoledipole. Wenner dengan spasi bervariasi dari 5 sampai $30 \mathrm{~cm}$ dan Dipole-dipole menggunakan spasi $5 \mathrm{~cm}, \mathrm{n}$ dari 1 sampai 8. Bola berbagai kadar digunakan sebagai target pada pemodelan fisis harus di ukur parameter fisisnya, meliputi berat, volume, densitas dan porositas. Metode pengukuran untuk memperoleh parameter fisis sampel menggunakan cara saturasi ${ }^{[11]}$, dilakukan di Laboratorium Batubara Jurusan Teknik Pertambangan UPN "Veteran" Yogyakarta.

Data yang diperoleh dari pengukuran respon TDIP dari berbagai kadar kedalaman target diolah dengan beberapa tahapan : (i) Pengeplotan dalam sayatan pseudodepth, untuk memperoleh gambaran distribusi resistivitas dan chargeabilitas di bawah permukaan. (ii) Pembuatan kurva profile untuk tiap-tiap lintasan pengukuran. (iii) Menganalisis hasil pseudosection konfigurasi Dipole-dipole dan Wenner. (iv) Melakukan inversi Res2Dinv dari data, untuk melihat distribusi resistivitas dan chargeabilitas nyata di bawah permukaan.

\section{HASIL DAN PEMBAHASAN}

Hasil pemodelan kedepan model geometri ideal dengan konfigurasi dua potensial dipermukaan, dengan variasi perbandingan resistivitas (resistivitas host $=r h o_{1}$ dan resistivitas target $=r h o_{2}$ ), dengan kondisi $R / d=1$ dan $1 / 3$, dimana $R=$ jari-jari bola dan $d$ adalah kedalaman. Kurva-kurva respon IP yang dihasilkan merupakan hubungan teoritis antara respon IP dan parameter bawah permukaan. Hasil menunjukkan bahwa kurva sangat smooth. Hal ini disebabkan karena penggunaan asumsi yang dipakai untuk menyederhanakan permasalahan. Pemodelan kedepan dibuat sesuai dengan kondisi pengukuran respon TDIP pada pemodelan fisis. Kurva hasil pemodelan kedepan bersesuaian dengan Telford ${ }^{[1]}$, Viezzoli ${ }^{[13]}$ dan Zhang ${ }^{[14]}$. 

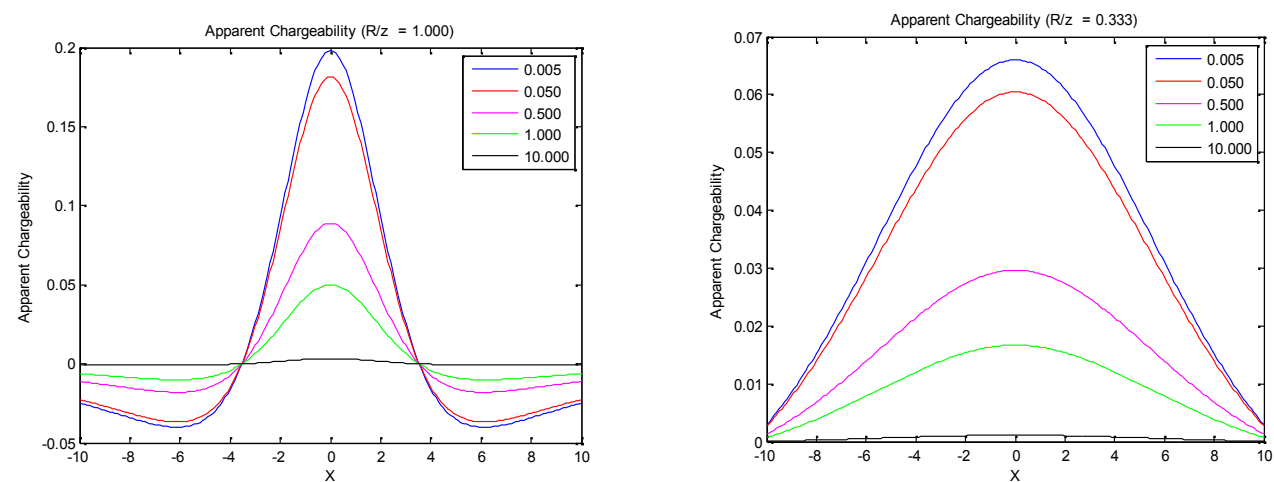

Gambar 2. (color online)Kurva hasil pemodelan kedepan berbagai perbandingan resistivitas untuk $R / d=1$ dan $1 / 3$

Hasil pemodelan kedepan respon IP berbagai kedalaman dan spasi konfigurasi Wenner dan berbagai resistivitas untuk $R / d=1$ dan $1 / 3$ ditunjukkan pada Gambar 2.
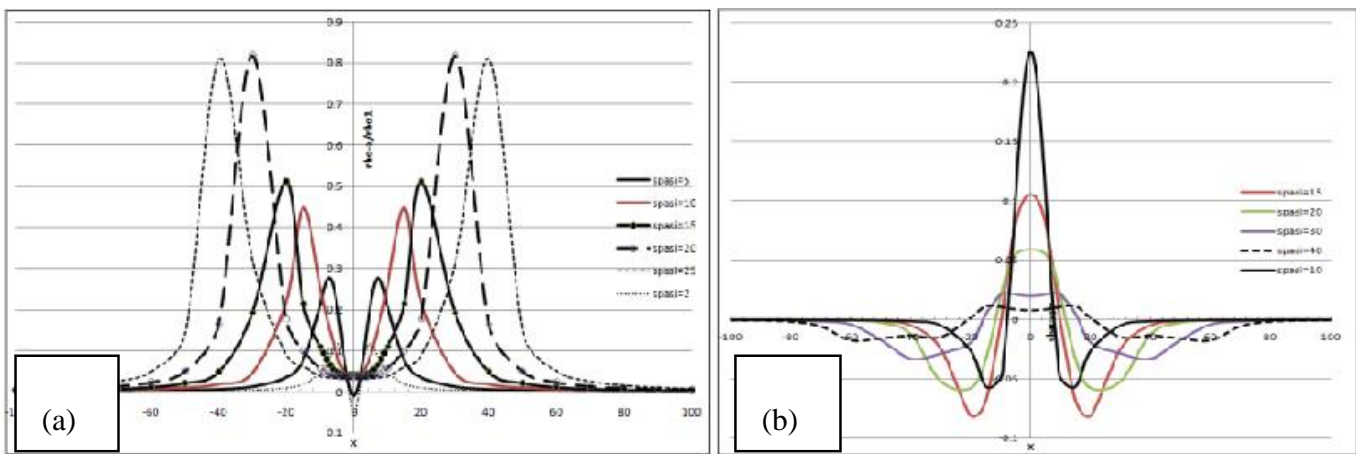

Gambar 3. (color online) Respon IP resistivitas (a) dan chargeabilitas (b) berbagai spasi elektroda dan spasi konfigurasi Wenner, $r h o l>r h o_{2}, \mathrm{~d} / \mathrm{R}=1$.

Gambar 3. menunjukkan kurva hasil pemodelan kedepan untuk berbagai $R / d$ untuk $r h o_{2} / r h o_{1}=1 / 2$. $r h o_{2}$ dan $r h o_{1}$ adalah resistivitas target dan host. Nilai rho $o_{1}$ diambil sebesar 20 Ohm-m, yang merupakan hasil pengukuran respon TDIP pada medium air tanah yang dipergunakan sebagai medium latar ${ }^{[7]}$.

Amplitudo respon IP ditentukan oleh rasio jari-jari dan kedalaman target dan rasio resistivitas medium latar dan target. Semakin besar rasio jari-jari, maka amplitudo respon IP semakin besar, untuk keadaan rasio resistivitas yang tertentu. Amplitudo respon TDIP konfigurasi Wenner, terbesar pada $d / R=1$. Hal ini berarti bahwa pada penggunaan konfigurasi Wenner dengan spasi 10, dengan posisi bola tepat dipermukaan akan menghasilkan pengukuran yang paling baik. Perubahan respon resistivitas terhadap spasi yang digunakan, semakin besar spasi maka respon yang tinggi bergeser. Hal ini menunjukkan bahwa pengukuran dengan konfigurasi Wenner, untuk posisi benda persis dibawah permukaan bagus menggunakan spasi yang kecil. Sedangkan untuk spasi yang besar respon diatas benda paling rendah, hal ini menunjukkan spasi besar tidak baik digunakan untuk posisi benda didekat permukaan.

Hasil pengukuran respon TDIP pada pemodelan fisis harus diplot dalam sayatan pseudodepth untuk mengetahui distribusi resistivitas dan chargeabilitas semu di bawah permukaan. Selain itu juga dibuat profile dengan cara melakukan pemfiliteran data pada 
setiap lintasan pengukuran. Profile ini akan dibandingkan dengan profile hasil pemodelan kedepan, untuk target bawah permukaan yang sudah ditentukan. Distribusi resistivitas dan chargeabilitas sebenarnya dibawah permukaan, didapat dari hasil pengolahan standar dengan inversi Res2DInv ${ }^{[12]}$. Contoh data hasil pengukuran TDIP pemodelan fisis dan hasil inversi Res2Dinv dengan target bola kadar $20 \%$ terletak $15 \mathrm{~cm}$ dibawah permukaan lintasan L0 pada Gambar 4. dan Gambar 5.

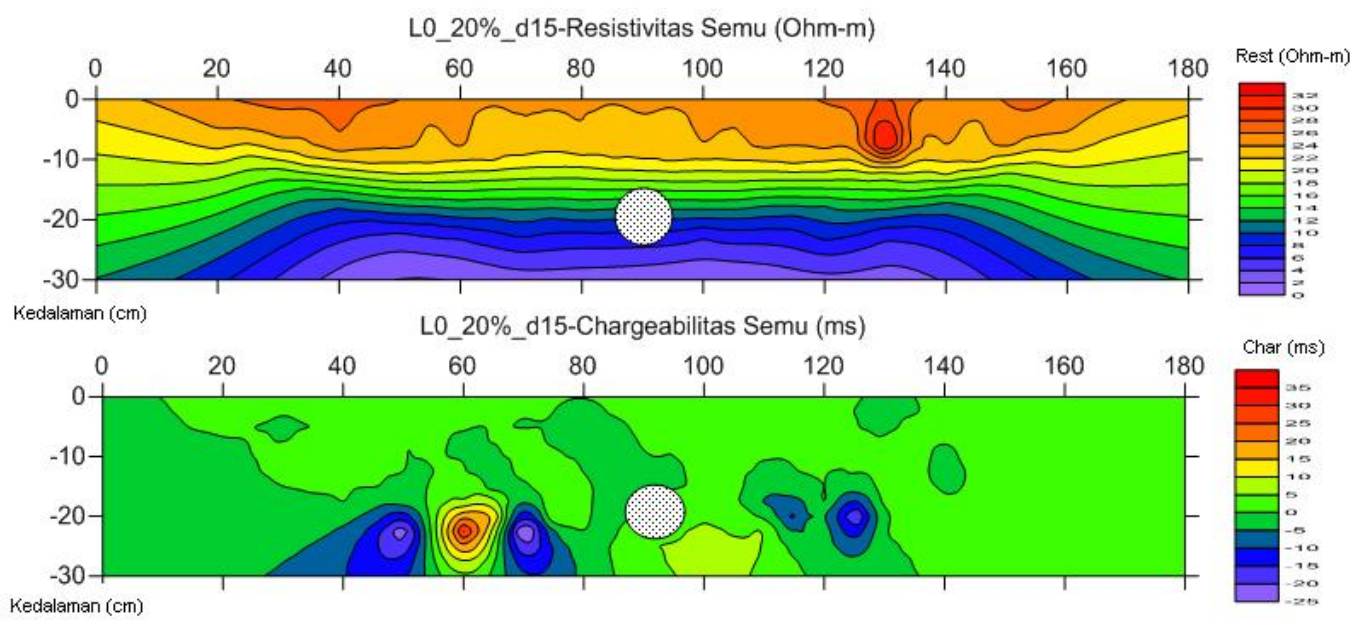

Gambar 4. (color online) Distribusi resistivitas dan chargeabilitas semu bawah permukaan lintasan L0, target bola kadar $20 \%$ dengan kedalaman $15 \mathrm{~cm}$.

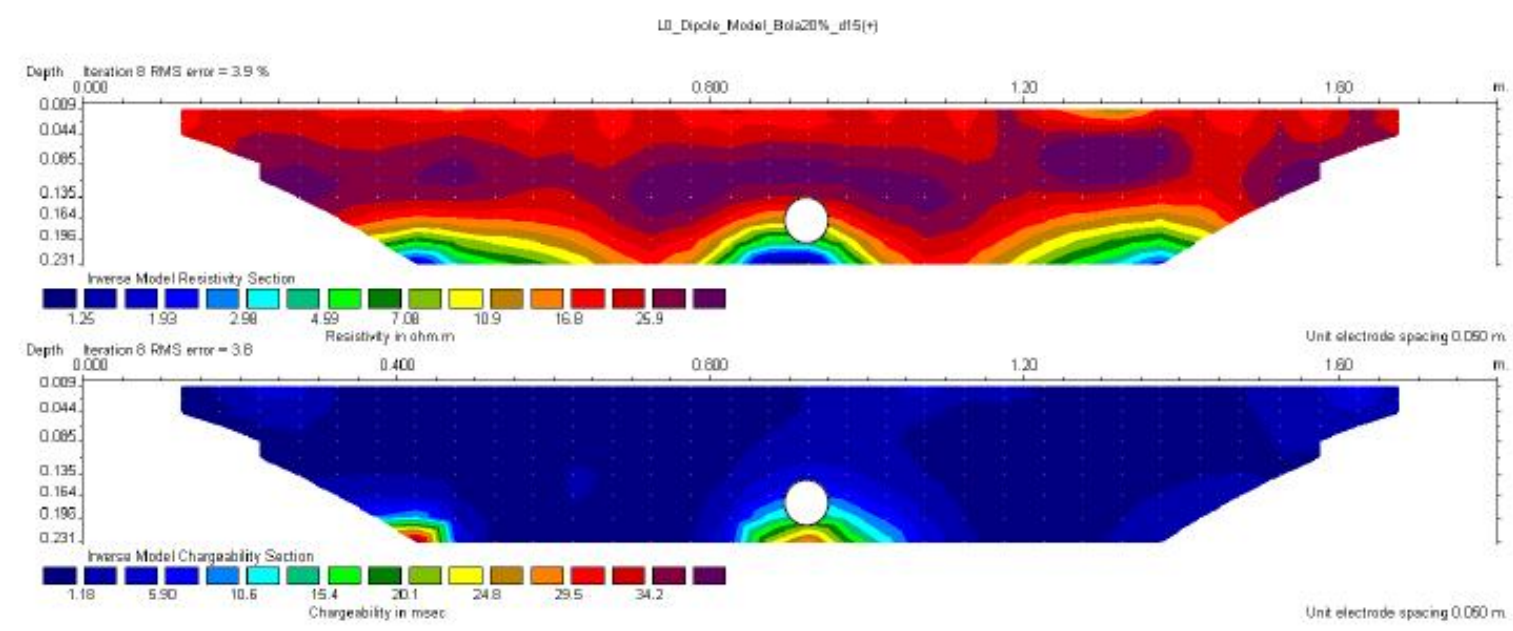

Gambar 5. (color online) Hasil pemodelan inversi Res2DInv lintasan L0, bola kadar 20\%, kedalaman $15 \mathrm{~cm}$

Distribusi nilai resistivitas dan chargeabilitas nyata dibawah permukaan ada pada Gambar 5. Hasil menunjukkan terdapat korelasi yang baik, antara respon TDIP hasil inversi Res2Dinv terhadap keberadaan target dan mungkin juga kandungan besi dalam target. Hasil inversi Res2Dinv untuk semua lintasan pengukuran menunjukkan closure nilai resistivitas rendah dan chargeabilitas yang tinggi ada pada kedalaman sekitar $20 \mathrm{~cm}$, walau pun letak target ada pada kedalaman 10, 20 dan $30 \mathrm{~cm}$. Hal ini menunjukkan bahwa kedalaman hasil inversi tidak berkorelasi kedalaman target.

Hal ini kemungkinan besar disebabkan oleh : (i) Penggunaan spasi $10 \mathrm{~cm}$ tidak sensitif terhadap perubahan perbadingan kedalaman dan jari-jari bola. (ii) Untuk konfigurasi Dipole-dipole penggunaan $\mathrm{n}=5$ sampai 8 memiliki sensitivitas yang semakin kecil, 
semakin kebawah sinyal semakin lemah. (iii) Pengaruh pemantulan sinyal dari dasar dan samping dinding pemodelan fisis sebagai noise.

Gambar 6 adalah contoh hasil ukur respon TDIP konfigurasi Dipole-dipole $n=1$ spasi 10 $\mathrm{cm}$ pada bola kadar $20 \%$, jari-jari $5 \mathrm{~cm}$ dan kedalaman $10 \mathrm{~cm}$.

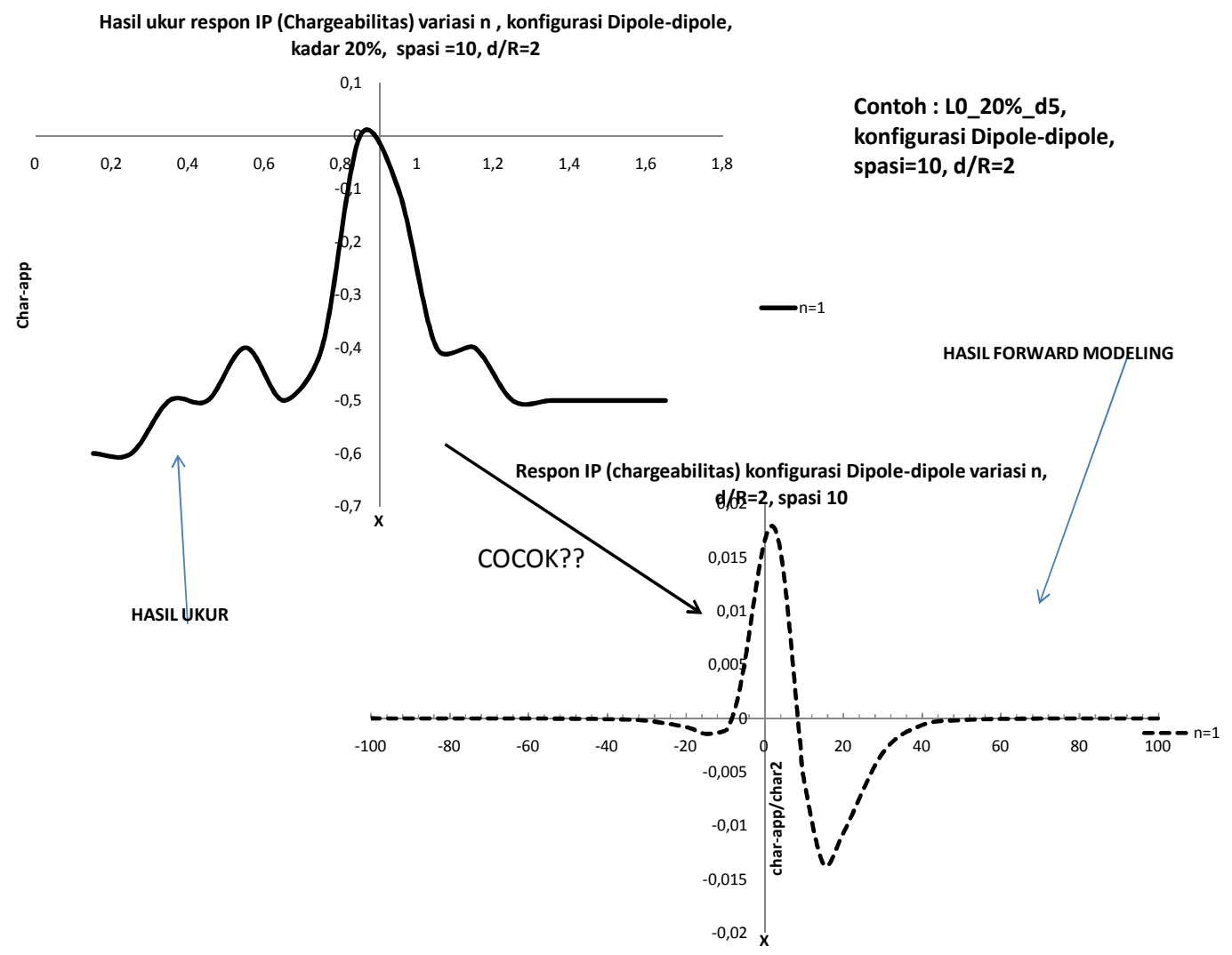

Gambar 6. Hasil pemodelan kedepan dan hasil ukur respon IP-chargeabilitas kofigurasi Dipole-dipole, bola bawah permukaan kadar $20 \%$, kedalaman $10 \mathrm{~cm}$, jari-jari $5 \mathrm{~cm}, d / R=2$

Hasil pemodelan kedepan harus dibandingkan (dicocokan) dengan data ukur respon TDIP pada pemodelan fisis. Pencocokan kurva ini disebut inversi. Perkiraan awal nilai resistivitas dan chargeabilitas memakai hasil pengukuran medium latar dan sampel. Selanjutnya dilakukan iterasi sehingga diperoleh kesalahan sekecil mungkin. Chargeabilitas target yang paling baik diharapkan diperoleh dari hasil inversi ini.

\section{KESIMPULAN}

Dalam penelitian "Studi Pemodelan Respon Polarisasi Terinduksi dalam Kawasan Waktu (TDIP) terhadap Kandungan Mineral Logam, sebuah hasil awal", dapat diambil beberapa kesimpulan.

Amplitudo respon IP untuk model benda ideal ditentukan oleh parameter bawah permukaan dan spasi yang digunakan. Amplitudo semakin kecil jika rasio kedalaman dan jari-jari semakin besar, sedangkan rasio resistivitas kedua medium berpengaruh kecil terhadap respon IP.

Hasil pemodelan kedepan respon IP, dapat digunakan untuk menentukan parameretisasi pada pemodelan fisis. 
Respon TDIP untuk model bola tepat dibawah permukaan, paling baik jika digunakan spasi kecil.

Terdapat korelasi yang baik, antara respon TDIP terhadap keberadaan target dan kemungkinan kandungan besi dalam target, tetapi tidak berkorelasi dengan kedalaman target.

Pemodelan inversi dilakukan untuk membandingkan hasil pemodelan kedepan dan respon hasil ukur pada pemodelan fisis, sehingga dihasilkan nilai chargeabilitas yang paling baik.

\section{UCAPAN TERIMAKASIH}

Penelitian ini dibiayai oleh Direktorat Jendral Pendidikan Tinggi Indonesia (DIKTI) dalam program Hibah Penelitian Doktor. Penulis mengucapkan terimakasih kepada Kementrian Pendidikan dan Kebudayaan Republik Indonesia. Penulis juga mengucapkan terimakasih kepada Wawan dan Sisca yang telah membantu pengambilan data. Kepada ketua Prodi Teknik Pertambangan dan Ketua Lab Batubara, UPN "Veteran" Yogyakarta yang telah mengijinkan tempat penelitian.

\section{DAFTAR PUSTAKA}

1 Telford, W.M., Geldart, L.P., Sherff, R.E., 1990, Applied Geophysics, Second Edition, Cambridge Univ.Press, London

2 Scott, W.J., and West, G.F., 1969, Induced Polarization of Synthetic, High-Resistivity Rock Containing Disseminated Sulfides, Geophysics, V.34, No.1 pp 87-100.

3 Vanhala, H., and Soininen, H., 1995, Laboratory Technigue for Measurement of Spectral IP Response of Soil Samples, Geophysical Prospecting, 43, 454-472.

4 Mansoor, N., dan Slater, L., 2007, On The Relationship Between Iron Concentration And Induced Polarization In Marsh Soils, Geophysics, Vol. 72, No. 1 JanuaryFebruary, p. A1-A5, 10.1190/1.2374853.

5 Slater, L.D., Ntarlagiannis, and D.Wishart, 2006, On the Relationship between Induced Polarization and Surface Area in Metal-Sand and Clay-Sand Mixtures, Geophysics, Vol.71, A1-A5.

6 Pelton, W.H., Ward, S.H., Hallof, P.G, Sill, W.R., Nelson, P.H., 1978, Mineral Discrimination and Removal of Inductive Coupling with Multi Frequency IP, Geophysics Vol.43 No.3, p.588-609.

7 Yatini, Santoso, D., Laesanpura, A., 2013, Physical Modelling Studies of the Time Domain Induced Polarization (TDIP) Response, Case : Homogeneous Isotropic Medium, Proceedings, 3rd Annual Basic Science International Conference (BaSIC), Malang.

8 Apparao. A., 1997, Development in Geoelectrical Methods, A.A. Balkema Publs, Old Post Road, Brookfield VT 05036, USA.

9 Apparao, A., Sivarama Sastry, R., and Sarma S.V., 1996, Depth Detection of Burried Resistive Target with Some Electrode Array in Resistivity Prospecting, Geophysical Prospecting, V.43. 
10 Yatini, Laesanpura, A., 2013, Influence of Potential's Electrode Election on Physical Modelling of Time Domain Induced Polarization (TDIP), Case Studies of Homogeneous Isotrop Medium, AIP Proceedings, Padjadjaran International Physics Symposium, Jawa Barat.

11 Franklin, J.A, Vogler, U.V., 1979, Suggested Methods for Determining Water Content, Porosity, Density, Absorption and Related Properties and Swelling and Slake-Durability Index Properties, Journal Rock Mechanic, Min Science and Geomechanics, 16, p141-156.

12 Loke, 2003, Electrical Imaging Surveys for Enviromental and Engineering Studies, A practical guide to 2-D and 3-D surveys.

13 Viezzoli, A., 2009, A Revised Mathematical Formulation For Induced Polarization, Proceeding, 20th International Geophysical Conference and Exhibition Adelaide, South Australia

14 Zhang, W., Jian-Xin Liu, Zhen-Wei Guo, dan Xiao-Zhong Tong, 2010, Cole-Cole Model Based on the Frequency-domain IP Method of Forward Modelling, Progress in Electromagnetics Research Symposium Proceedings, Xi'an, China. 